\title{
Teores elevados em folhas de árvores dos metais cádmio, níquel e manganês dispersos no ar por laboratórios de análises químicas
}

High levels in leaves of trees for cadmium, nickel and manganese dispersed in the air for chemical analysis laboratories

Los niveles altos en las hojas de los árboles para el cadmio, níquel y manganeso dispersadas en el aire para los laboratorios de análisis químico

Mariana Rojas Fernandes Mestranda, UNESP, Brasil ma_rojasf@hotmail.com

Flávio Fernando Manzini Professor Doutor, UNESP, Brasil fmanzini@ibilce.unesp.br

Lidia Maria de Almeida Plicas Professora Doutora, UNESP, Brasil plicas@ibilce.unesp.br 


\title{
RESUMO
}

Nesse estudo foram submetidas folhas de pinheiro, bananeira, abacateiro, mangueira e goiabeira a ensaios analíticos para se determinar as concentrações dos metais potencialmente tóxicos cádmio, níquel e manganês. Essas folhas foram coletadas de árvores que se encontravam dentro da área do Instituto de Biociências, Letras e Ciências Exatas, da UNESP, campus de São José do Rio Preto e que estão sujeitas a absorver os resíduos provenientes de exaustores, sem filtros adequados, dos vários laboratórios do instituto, em especial daqueles ligados aos cursos de Ciências Biológicas, Engenharia de Alimentos e Química. As folhas foram higienizadas e secas em estufa. Procedeu-se, então, à digestão úmida desse material pela combinação dos ácidos nítrico e perclórico na proporção 3:1, concentrados. As análises foram feitas em triplicata e submetidas à espectrometria de absorção atômica, por atomização em chama. Os resultados obtidos indicaram, para as folhas, altas concentrações dos metais cádmio e níquel em todas e concentração muito elevada de manganês somente nas folhas de mangueira.

PALAVRAS-CHAVE: Análises químicas, Metais potencialmente tóxicos, Tecido vegetal

\begin{abstract}
In this study were submitted pine, banana, avocado, mango and guava leaves to analytical tests to determine the concentrations of potentially toxic metals cadmium, nickel and manganese. These leaves were collected from trees that were in the Instituto de Biociências, Letras e Ciências Exatas, UNESP, São José do Rio Preto and are subject to absorb the waste from exhaust without appropriate filters from various institute's laboratories, especially those linked to the courses of Biological Sciences, Food Engineering and Chemistry. The sheets were cleaned and oven dried. The procedure was then the wet digestion of this material by a combination of nitric and perchloric acid in the ratio 3:1 concentrated. Analyses were performed in triplicate and submitted to atomic absorption spectrometry, flame spray. The results indicated, for the sheets, high concentrations of cadmium and nickel metals at all and very high concentration of manganese in the hose leaves only.
\end{abstract}

KEY-WORDS: Chemical analysis, Potentially toxic metals, Plant tissue

\section{RESUMEN}

En este estudio se presentaron pino, plátano, aguacate, mango y guayaba deja a pruebas analíticas para determinar las concentraciones de metales potencialmente tóxicos de cadmio, níquel y manganeso. Estas hojas se recogen de los árboles que se encontraban en el Instituto de Biociencias, Letras E Ciências Exatas, UNESP, São José do Rio Preto y están sujetos a absorber los residuos de escape, sin filtros adecuados de diversos laboratorios em el instituto, especialmente los vinculados a los cursos de Ciencias Biológicas, Ingeniería de Alimentos y Química. Las láminas se limpiaron y se secaron al horno. El procedimiento fue entonces la digestión húmeda de este material por una combinación de ácido nítrico y ácido perclórico en la relación de 3: 1 se concentró. Los análisis se realizaron por triplicado y se sometieron a espectrometría de absorción atómica, pulverización a la llama. Los resultados indicaron, para las hojas, las altas concentraciones de metales cadmio y níquel en absoluto y muy alta concentración de manganeso en la manguera de hojas solamente.

PALABRAS-CLAVE: Los análisis químicos, Metales potencialmente tóxicos, Tejidos de la planta 


\section{INTRODUÇÃO}

A análise química quantitativa de tecidos vegetais é um dos métodos utilizados para avaliar o estado nutricional das plantas, pois constitui uma medida direta da disponibilidade de nutrientes no solo, uma vez que os resultados correspondem à quantidade de nutrientes absorvida pelas plantas. Dessa forma, o teor de nutrientes nos tecidos vegetais reflete sua real disponibilidade no solo, porque existe relação direta entre o fornecimento de um nutriente pelo solo ou por um fertilizante e sua concentração nas folhas e nos frutos, e há relação também direta entre essa concentração e a produção da cultura (BERNARDI et al., 2010). Essa ferramenta pode ser utilizada, também, para a deteç̧ão e quantificação de metais potencialmente tóxicos, presentes no solo e/ou em insumos agrícolas. A análise foliar é uma técnica que avalia a concentração de elementos em uma determinada parte da planta, pois dentre todos os órgãos da planta, normalmente a folha é que reflete melhor o estado nutricional de carência ou excesso. Essa análise pode, também, ser realizada a partir do fruto, porém, menos comum (CARNIERI et al., 1999).

Dentre os metais necessários ao metabolismo animal e vegetal, estão os chamados micronutrientes, que incluem metais como o manganês e o níquel. No entanto, quando estes estão presentes nos alimentos em concentrações elevadas, podem ser absorvidos e se acumular nos tecidos manifestando-se prejudicial. A toxicidade de um composto qualquer, incluindo os metais, está diretamente relacionada à dose, ao tempo de exposição, à forma física e química dos elementos, da via de administração e da absorção. O metal cádmio não é essencial ao processo metabólico sendo reconhecido como tóxico (OMS, 1998 apud Venezuela, 2001).

Atualmente o níquel já pode ser considerado um elemento essencial para as plantas em doses adequadas, uma vez que participa da atividade da uréase. Seu excesso é prejudicial. É considerado um elemento carcinogênico às vias respiratórias dos seres humanos. A presença de cádmio em plantas diminui o potencial de absorção de nutrientes. No ser humano pode provocar elevação da pressão sanguínea, aumento do coração, queda da imunidade, enfraquecimento ósseo, dores nas articulações, anemia, enfisema pulmonar e osteoporose, dentre outros (MALLAGOLI et al., 2013).

\subsection{Sobre metais potencialmente tóxicos}

De acordo com Moura (2009):

\footnotetext{
Metais pesados, contaminantes, elementos potencialmente tóxicos ou elementos não nutrientes? Não há correta definição, segundo a IUPAC há uma ampla tentativa de conceituar e definir o termo "metal pesado", porém cada "metal" deve ser estudado separadamente de acordo com suas características químicas, biológicas e propriedades toxicológicas.........para os (metais) até então sem função conhecida para as plantas, tais como: cádmio $(\mathrm{Cd})$, crômio $(\mathrm{Cr})$ e chumbo $(\mathrm{Pb})$, será usado o termo "metais pesados tóxicos", vale ressaltar que qualquer macro, micronutriente ou elemento benéfico pode tornar-se tóxico quando em concentração excessiva no meio, ou seja, "a dose faz o veneno.
} 
Conforme Belluta et al. (2008) as principais fontes dos metais potencialmente tóxicos, como $\mathrm{Cd}, \mathrm{Cu}, \mathrm{Ni}, \mathrm{Pb}, \mathrm{Zn}$, são os fertilizantes e pesticidas utilizados na agricultura, além da queima de combustíveis fósseis que emitem particulados que se dispersam na atmosfera, precipitam no solo e contaminam os corpos de águas. Estes metais também são lixiviados dos resíduos de baterias, pigmentos e tintas, do uso médico e de aditivos em combustíveis e lubrificantes.

Esses elementos possuem a tendência em formar ligações reversíveis, além de não serem biodegradáveis. Nas membranas das células reagem com ligantes, o que Ihes confere as propriedades de bioacumulação e biomagnificação. A bioacululação é a soma da incorporação de um xenobiótico efetuada por ingestão ou contaminação. Esse processo é mais frequente em organismos aquáticos. A biomagnificação é a transferência de um xenobiótico por meio da cadeia alimentar, podendo causar sérios problemas aos organismos vivos, já que os níveis aumentam progressivamente ao longo da cadeia trófica, atingindo níveis elevados nos organismos predadores que ocupam seu topo, promovendo também a persistência no ambiente, fator que garante que os efeitos continuem ao longo do tempo mesmo depois de cessadas suas emissões. Os processos de bioacumulação e biomagnificação se encarregam de transformar concentrações consideradas normais em concentrações tóxicas para diferentes espécies da biota e para a espécie humana. (TOMAZELLI, 2003, BAIRD; CANN, 2011, TAVARES, 1992 apud MARTINS, 2012).

O Cádmio é um metal de transição que pertence ao grupo 12 da tabela periódica. Possui numero atômico 48, cor branca prateada e apresenta ductibilidade. Trata-se de um metal reativo, sendo encontrado associado a sulfitos, minério de zinco, chumbo e cobre. A utilização usual deste metal se dá na fabricação de tintas e na confecção de ligas metálicas, cigarros, farinhas refinadas, materiais odontológicos e na indústria de aço. É disponibilizado ao meio por emissões gasosas industriais, fertilizantes, pesticidas, fungicidas e materiais cerâmicos. Pode ser liberado de resíduos de solda e pilhas elétricas. Encontra-se, ainda, em quantidades importantes em frutos do mar e farinha de ossos. Na natureza, são liberados durante atividade vulcânica, na erosão de rochas sedimentares e em queimadas em florestas. O cádmio é encontrado em toda crosta terrestre. Rochas sedimentares e fosfatos marinhos podem apresentar concentrações do metal, que chegam a $15 \mathrm{mg} \mathrm{kg}^{-1}$, valor considerado muito alto (MALLAGOLI et al., 2013).

A alimentação é a principal fonte de exposição ao cádmio para a população geral e não fumante. Carnes, peixes, ovos e laticínios contêm pouca concentração do metal (menos de $0,01 \mu \mathrm{g} \mathrm{g}^{-1}$ de peso úmido), já os órgãos internos, especialmente fígado e rins, podem conter concentrações mais elevadas. Os vegetais apresentam mais cádmio que os produtos de origem animal. Os fumantes constituem um grupo de alta exposição, já que as folhas de tabaco acumulam naturalmente altas concentrações do metal (CETESB/FIT - Cádmio, 2012).

Com relação à saúde humana, a toxicidade depende dos níveis orgânicos dos íons protetores zinco II, cobre II, ferro II e cálcio II, que dificultam a absorção do metal no organismo. Algumas das doenças provocadas por intoxicação ao metal são: fibrose e edema pulmonar, doenças renais com proteinúria e glicosúria, hipertesão arterial, diminuição da produção de anticorpos, anemia e diminuição da testosterona (MIGUEL JUNIOR, 2008). 
Nas plantas, um dos sintomas típicos visíveis da toxidade ao cádmio é a clorose foliar que ocorre em maior proporção nas folhas novas demonstrando-se estas, mais vulneráveis à toxidez. Quando intoxicadas por cádmio, ocorre a inibição da atividade fotossintética afetando a absorção, o transporte e o aproveitamento de macroelementos como cálcio, fósforo, potássio e enxofre, assim como da água. Há relatos de plantas hiperacumuladoras de metais pesados, que possuem a capacidade de se desenvolver em solos ricos em metais, capazes de acumular altos níveis desses metais tóxicos, atuando como estratégia de remediação para esses solos (GUIMARÃES et al., 2008). O Quadro 1 apresenta padrões e valores orientadores para o cádmio em diversos compartimentos ambientais (CETESB/FIT-CÁDMIO, 2012).

Quadro 1. Padrões e valores orientadores para o cádmio em diversos compartimentos ambientais.

\begin{tabular}{|c|c|c|c|}
\hline Meio & Concentração & Comentário & Referência \\
\hline Solo & $\begin{array}{l}1,3 \mathrm{mg} / \mathrm{kg}^{*} \\
3 \mathrm{mg} / \mathrm{kg}^{*} \\
8 \mathrm{mg} / \mathrm{kg}^{*} \\
20 \mathrm{mg} / \mathrm{kg}^{*}\end{array}$ & $\begin{array}{l}\text { Valor de Prevenção } \\
\text { VI cenário agrícola-APMax } \\
\text { VI cenário residencial } \\
\text { VI cenário industrial }\end{array}$ & CONAMA 420/2009 \\
\hline Água potável & $0,005 \mathrm{mg} / \mathrm{L}$ & Padrão de potabilidade & PORTARIA 2914/2011 \\
\hline $\begin{array}{l}\text { Água } \\
\text { subterrânea }\end{array}$ & $\begin{array}{c}5 \mu \mathrm{g} / \mathrm{L} \\
50 \mu \mathrm{g} / \mathrm{L} \\
10 \mu \mathrm{g} / \mathrm{L} \\
5 \mu \mathrm{g} / \mathrm{L}\end{array}$ & $\begin{array}{l}\text { VMP|(consumo humano) } \\
\text { VMP (dessedentação de } \\
\text { animais) } \\
\text { VMP (irrigação) } \\
\text { VMP (recreação) }\end{array}$ & CONAMA 396/2008 \\
\hline Águas doces & $\begin{array}{l}0,001 \mathrm{mg} / \mathrm{L} \\
0,01 \mathrm{mg} / \mathrm{L}\end{array}$ & $\begin{array}{l}\text { VM (classes } 1 \text { e } 2 \text { ) } \\
\text { VM (classe } 3 \text { ) }\end{array}$ & CONAMA 357/2005 \\
\hline Águas salinas & $\begin{array}{c}0,005 \mathrm{mg} / \mathrm{L} \\
0,04 \mathrm{mg} / \mathrm{L}\end{array}$ & $\begin{array}{l}\text { VM (classe 1) } \\
\text { VM (classe 2) }\end{array}$ & CONAMA 357/2005 \\
\hline $\begin{array}{l}\text { Águas } \\
\text { salobras }\end{array}$ & $\begin{array}{l}0,005 \mathrm{mg} / \mathrm{L} \\
0,04 \mathrm{mg} / \mathrm{L}\end{array}$ & $\begin{array}{l}\text { VM (classe 1) } \\
\text { VM (classe 2) }\end{array}$ & CONAMA 357/2005 \\
\hline
\end{tabular}

O níquel é um metal de transição prateado, de numero atômico 28 , pertencente ao grupo 2B da tabela periódica, dúctil e maleável. Forma compostos inorgânicos solúveis, como hidróxidos, sulfatos, cloretos e nitratos e orgânicos insolúveis, como óxidos e sulfetos (CETESB/FIT-NÍQUEL, 2012). É utilizado na fabricação de aço inoxidável, de baterias recarregáveis, em reações de catálise, em cunhagens de moedas, em revestimentos metálicos, na fundição, como catalisador da hidrogenação de óleos vegetais (PCEX, 2010). Sua alta concentração no solo provém de atividades antropogênicas, principalmente, relacionadas à utilização de fertilizantes fosfatados, à queima de combustíveis fósseis e óleos e à aplicação de resíduos de lodo no solo (MALLAGOLI et al., 2013).

O níquel emitido por suas diversas fontes percorre todos os compartimentos ambientais, podendo ser depositado nos sedimentos por processos de precipitação, complexação, adsorção em argila e assim se agrega à biota.

O níquel é um elemento essencial ao organismo humano desde que não em excesso. Está envolvido na atividade enzimática e hormonal, na estabilidade estrutural das macromoléculas 
biológicas e no metabolismo em geral. Em altas concentrações pode ser tóxico, causando moléstias tais como: dermatite de contato, úlceras, aumento dos glóbulos vermelhos e perda de proteínas pela urina, bronquite crônica e câncer de pulmão (CETESB/FIT-NÍQUEL, 2012).

Os vegetais são os alimentos que mais concentram o metal. Nas plantas, atua no metabolismo do nitrogênio aumentando a urease foliar, impedindo a acumulação em excesso de uréia. Atua no crescimento, no metabolismo, na absorção de ferro e, também, auxilia na resistência das plantas às doenças. Seu excesso, nas plantas, pode causar clorose (pelo fato de inibir a absorção de ferro), crescimento reduzido das raízes, além de desenvolvimento anormal de partes da planta (E-CENTRO, 2012; LABORSOLO, 2013). O Quadro 2 apresenta padrões e valores orientadores para o níquel em diversos compartimentos ambientais (CETESB/FITNÍQUEL, 2012).

Quadro 2. Padrões e valores orientadores para o níquel em diversos compartimentos ambientais.

\begin{tabular}{|c|c|c|c|}
\hline \multicolumn{4}{|c|}{ Padrões e valores orientadores } \\
\hline Meio & Concentração & Comentário & Referência \\
\hline Efluente $^{1}$ & $2,0 \mathrm{mg} / \mathrm{L}$ & VM (Padrão de lançamento) & $\begin{array}{l}\text { CONAMA } \\
430 / 2011\end{array}$ \\
\hline Solo & $\begin{array}{c}30 \mathrm{mg} / \mathrm{kg}^{*} \\
70 \mathrm{mg} / \mathrm{kg}^{*} \\
100 \mathrm{mg} / \mathrm{kg}^{*} \\
130 \mathrm{mg} / \mathrm{kg}^{*}\end{array}$ & $\begin{array}{l}\text { Valor de Prevenção } \\
\text { VI cenário agrícola-APMax } \\
\text { VI cenário residencial } \\
\text { VI cenário industrial }\end{array}$ & $\begin{array}{l}\text { CONAMA } \\
420 / 2009\end{array}$ \\
\hline Água potável & $0,07 \mathrm{mg} / \mathrm{L}$ & Padrão de potabilidade & $\begin{array}{l}\text { PORTARIA } \\
2914 / 2011\end{array}$ \\
\hline $\begin{array}{l}\text { Água } \\
\text { subterrânea }\end{array}$ & $\begin{array}{c}20 \mu \mathrm{g} / \mathrm{L} \\
1000 \mu \mathrm{g} / \mathrm{L} \\
200 \mu \mathrm{g} / \mathrm{L} \\
100 \mu \mathrm{g} / \mathrm{L}\end{array}$ & $\begin{array}{l}\text { VMP (consumo humano) } \\
\text { VMP (dessedentação de animais) } \\
\text { VMP (irrigação) } \\
\text { VMP (recreação) }\end{array}$ & $\begin{array}{l}\text { CONAMA } \\
396 / 2008\end{array}$ \\
\hline Águas doces & $0,025 \mathrm{mg} / \mathrm{L}$ & VM (classes 1, 2 e3) & $\begin{array}{l}\text { CONAMA } \\
357 / 2005\end{array}$ \\
\hline Águas salinas & $\begin{array}{l}0,025 \mathrm{mg} / \mathrm{L} \\
74 \mu \mathrm{g} / \mathrm{L}\end{array}$ & $\begin{array}{l}\text { VM (classes 1) } \\
\text { VM (classe 2) }\end{array}$ & $\begin{array}{l}\text { CONAMA } \\
357 / 2005\end{array}$ \\
\hline $\begin{array}{l}\text { Águas } \\
\text { salobras }\end{array}$ & $\begin{array}{l}0,025 \mathrm{mg} / \mathrm{L} \\
74 \mu \mathrm{g} / \mathrm{L}\end{array}$ & $\begin{array}{l}\text { VM (classe 1) } \\
\text { VM (classe } 2 \text { ) }\end{array}$ & $\begin{array}{l}\text { CONAMA } \\
357 / 2005\end{array}$ \\
\hline $\begin{array}{l}1 \text { = níquel tota } \\
\text { Investigação; } V\end{array}$ & $\begin{array}{l}=\text { peso seco } \\
=\text { Valor Máxim }\end{array}$ & $\begin{array}{l}\text { APMAx = Área de Proteção IMáxim } \\
\text { Permitido; VM = Valor Máxinıo }\end{array}$ & $\mathrm{VI}=$ Valor $\mathrm{de}$ \\
\hline
\end{tabular}

O manganês é um metal acinzentado, de numero atômico 25 que pertence ao grupo 7B (metais de transição) da tabela periódica. Apresenta-se duro e quebradiço sendo encontrado na forma de óxidos, hidróxidos, silicatos e carbonatos, devido à sua alta reatividade (SANTIAGO, 2006).

Em sua forma inorgânica é utilizado na fabricação de ligas metálicas para pilhas, em fósforos, na fabricação de vidros e de fogos de artifício, na indústria química, de couro e têxtil, e na fórmula de fertilizantes. O permanganato de potássio é usado como oxidante, branqueador e no tratamento de doenças da pele. Em sua forma orgânica é utilizado, principalmente, em aditivos para gasolina e em praguicidas. Na atmosfera se encontra particulado e em suspensão como resultado da erosão do solo, de emissões industriais e vulcânicas e da queima de 
gasolina contendo TMM (tricarbonil metilciclopentadienil manganês). Essas partículas podem ser alteradas por atividade microbiológica (PRATES, 2011).

As águas subterrâneas anaeróbias podem conter níveis elevados de manganês dissolvido. Em rios, o metal é adsorvido em partículas suspensas dos sedimentos. O composto orgânico TMM, apresenta persistência no ambiente aquático e no solo na ausência de luz solar, sorvendo com facilidade às partículas do solo e sedimento. Já na presença de luz, a fotodegradação do TMM é rápida (menos de dois minutos). Os organismos nos quais o manganês pode se acumular são, principalmente, as algas, os moluscos e alguns peixes, porém a biomagnificação na cadeia alimentar ocorre de forma não significativa, fato justificado uma vez que a bioacumulação do manganês é maior em níveis tróficos inferiores.

O manganês é essencial a todos os organismos. Participa das enzimas fosfotransferases e no processo de fotossíntese. Pode ser encontrado, mais comumente, nos cereais integrais, legumes, verduras e frutas. No metabolismo humano é responsável pela ativação de enzimas implicadas na síntese do tecido conjuntivo, proteção das células contra radicais livres e nas atividades neuro-hormonais, sendo assim, auxilia em processos de estabilização da glicemia, da metabolização de gorduras, da proteção das células hepáticas, da biossintetização das proteínas e dos muco-polissacarídeos das cartilagens, assim como no metabolismo dos neurotransmissores. Sua deficiência pode causar perda de peso, problemas na capacidade reprodutiva, anormalidades no esqueleto e prejuízo no crescimento (ROCHA e AFONSO, 2012). Já o excesso deste metal pode causar inflamação nos pulmões e ao atingir o sistema nervoso central causar alucinações, fraqueza, distúrbios de comportamento e fala culminando em uma doença semelhante ao mal de Parkinson, denominada manganismo (ALVES, 2014; CETESB/FITMANGANÊS, 2012).

Nas plantas, funciona, principalmente, como parte dos sistemas enzimáticos e processos importantes como a fotossíntese e a conversão do $\mathrm{N}$-nitrato de forma que a planta possa utilizar esse composto para a síntese de aminoácidos e proteínas. A síntese de clorofila também depende do manganês, portanto, sua deficiência causa amarelamento e clorose das folhas. Quando em excesso, a parte aérea da planta é a mais afetada pela toxidez sendo as manchas marrons nas folhas os sintomas mais visíveis em plantas jovens. Os danos às raízes se manifestam mais tarde (BRAGA, 2011; VIEIRA, 2011). O Quadro 3 apresenta padrões e valores orientadores para o níquel em diversos compartimentos ambientais (CETESB/FIT-MANGANÊS, 2012). 
Quadro 3. Padrões e valores orientadores para o manganês em diversos compartimentos ambientais.

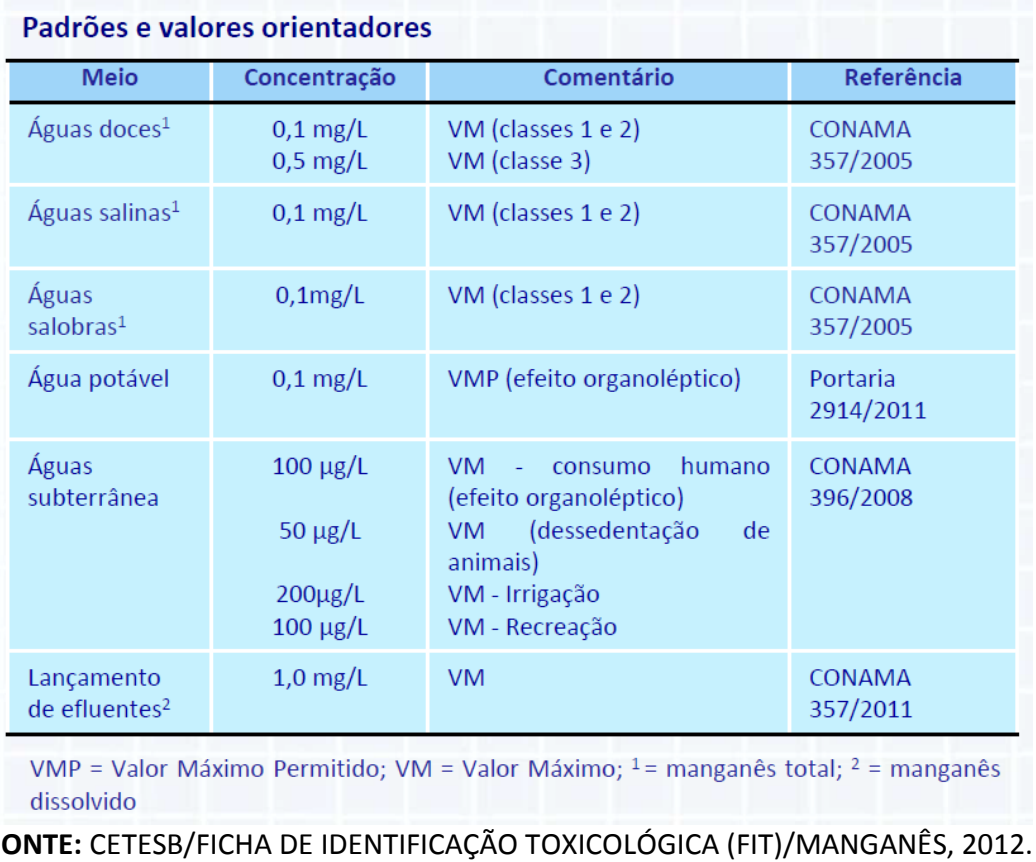

\section{OBJETIVO}

Nesse projeto objetivou-se a aplicação de método analítico para extração e determinação das concentrações dos metais manganês, cádmio e níquel em amostras do tecido vegetal de folhas de pinheiro, bananeira, mangueira, goiabeira e abacateiro sujeitos à absorção de resíduos aéreos oriundos da atividade química laboratorial para se comparar com os parâmetros existentes para teores limites dos mesmos.

\section{MÉTODO DE ANÁLISE}

\subsection{MATERIAIS}

Para o desenvolvimento do projeto foram utilizadas folhas de pinheiro, bananeira, mangueira, goiabeira e abacateiro.

Foram utilizadas vidrarias, acessórios e equipamentos de laboratório adequados, tais como béqueres, provetas, pipetas, erlenmeyers, balões volumétricos, almofarizes e pistilos de cerâmica, reagentes de grau analítico e água destilada, estufa, membranas filtradoras, filtro, bomba de vácuo, balança analítica, bloco digestor, dentre outros.

As amostras foram processadas em espectrômetro de absorção atômica por emissão de chama, modelo SpectrAA 50B, da marca Varian. 


\subsection{MÉTODOS}

\subsubsection{Metodologia de coleta e tratamento das amostras (SILVA, 2009)}

As folhas das plantas acima citadas foram coletadas dentro do perímetro do campus da UNESP, de São José do Rio Preto. Procurou-se coletar folhas verdes, em bom estado de conservação. Essas folhas foram submetidas à lavagem com água de torneira e enxaguadas com água destilada. Após esse procedimento, as amostras foram secas em estufa à temperatura $\leq 60$ C. A seguir, após a desidratação das amostras, as mesmas foram maceradas em almofariz sendo que, o material pulverizado foi acondicionado em frascos de vidro escuro e reservado em geladeira.

\subsubsection{Metodologia de extração e determinação das concentrações dos metais cádmio, níquel e manganês (SILVA, 2009)}

O método analítico utilizado no projeto para a extração dos metais foi a digestão úmida pela combinação dos ácidos nítrico e perclórico $\left[\mathrm{HNO}_{3}+\mathrm{HClO}_{4}(3: 1)\right]$.

Dessa forma, pesou-se $500 \mathrm{mg}$ de amostra previamente desidratada e se transferiu para um erlenmeyer de $125 \mathrm{~mL}$. Foram adicionados $8 \mathrm{~mL}$ da solução ácida $\mathrm{HNO}_{3}+\mathrm{HClO}_{4}$. Esse sistema foi mantido a frio pelo período de 3 horas.

$\mathrm{Na}$ sequência foi transferido para um bloco digestor e aquecido a 120 으 até cessar o desprendimento de vapores de coloração acastanhada característica de $\mathrm{NO}_{2}$ (dióxido de nitrogênio).

Em seguida, a temperatura foi elevada a $200^{\circ} \mathrm{C}$ até cessar o desprendimento de vapores esbranquiçados característicos do $\mathrm{HClO}_{4}$.

Após o resfriamento do sistema completou-se o volume para $25 \mathrm{~mL}$ com água destilada transferindo-se para frasco de vidro escuro.

As amostras foram, então, submetidas à análise por espectrometria de absorção atômica (EAA) por emissão de chama nos comprimentos de onda: $\mathrm{Mn}^{2+}=403,1 \mathrm{~nm}, \mathrm{Cd}^{2+}=228,9 \mathrm{~nm}$ e $\mathrm{Ni}^{2+}=232,0 \mathrm{~nm}$. No caso da análise para o metal níquel, foram acrescentadas duas gotas de ácido nítrico para estabilizar a solução, facilitando a sensibilidade de detecção no espectrômetro para um menor comprimento de onda.

\section{RESULTADOS}

Os parâmetros orientadores para os teores do metal manganês em folhas se encontram no quadro 4. Os valores orientadores para cádmio e níquel estão apresentados no Quadro 5. Todas as análises foram feitas em triplicata. 
Quadro 4. Limites máximos permitidos para concentração de manganês nas plantas.

\begin{tabular}{|c|c|}
\hline Planta (folha) & {$\left[\mathbf{M n}^{2+}\right] \mathbf{~ m g ~ k g}^{-\mathbf{1}}$} \\
\hline Pinheiro & $200,0-300,0$ \\
\hline Bananeira & $200,0-2000,0$ \\
\hline Mangueira & 120,0 \\
\hline Goiabeira & $202,0-398,0$ \\
\hline Abacateiro & $30,0-500,0$ \\
\hline
\end{tabular}

FONTE: FAQUIN, 2002

Quadro 5. Limites máximos permitidos para concentração de cádmio e níquel nas plantas.

\begin{tabular}{|c|c|}
\hline$\left[\mathrm{Cd}^{2+}\right] \mathbf{~ m g ~ k g}^{-1}(\mathbf{1})$ & {$\left[\mathbf{N i}^{2+}\right] \mathbf{~ m g ~ k g}^{-1}(\mathbf{2})$} \\
\hline$<0,0571$ & $0,02-5,00$ \\
\hline
\end{tabular}

FONTE: (1)DIÁRIO OFICIAL DA UNIÃO (2013), (2)GOVERNO DO BRASIL/CONAMA

Os gráficos obtidos das curvas-padrão dos metais manganês, cádmio e níquel dos extratos das folhas e dos frutos estão ilustrados pelas figuras 1, 2 e 3. Em todos o coeficiente de correlação $\left(R^{2}\right)$ mostrou-se excelente com valores muito próximos a 1.

As concentrações obtidas para os metais manganês, cádmio e níquel das amostras de folhas analisadas se encontram no Quadro 6.

Figura 1. Curva-padrão utilizada para se estabelecer as concentrações de $\mathrm{Mn}^{2+}$ disponível das amostras de folhas, segundo a média dos valores das amostras em triplicatas, em $\lambda=403,1 \mathrm{~nm}$

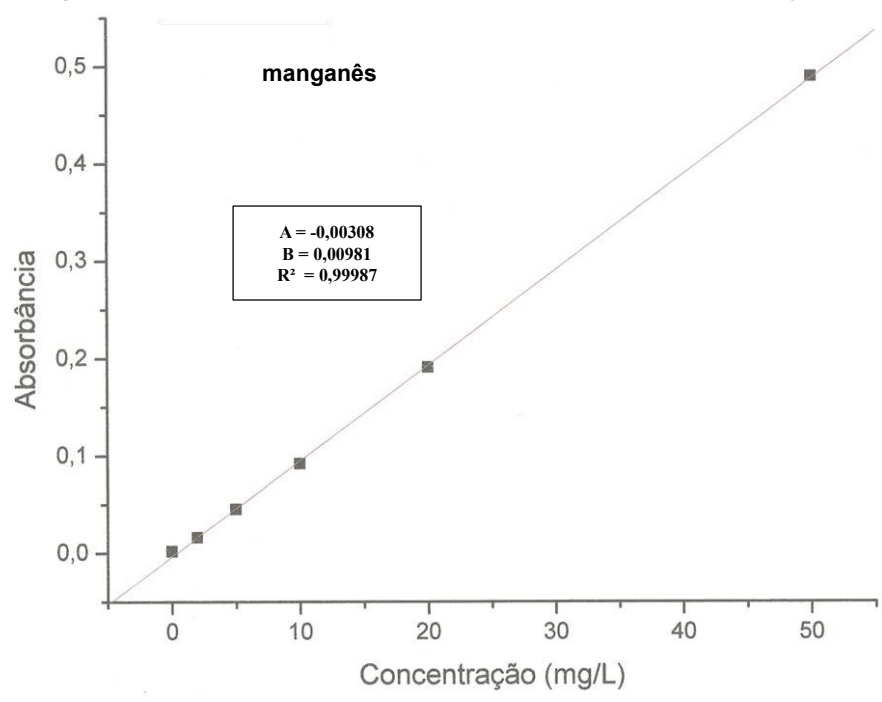


Figura 2. Curva-padrão utilizada para se estabelecer as concentrações de $\mathrm{Cd}^{2+}$ disponível das amostras de folhas, segundo a média dos valores das amostras em triplicatas, em $\lambda=228,8 \mathrm{~nm}$.

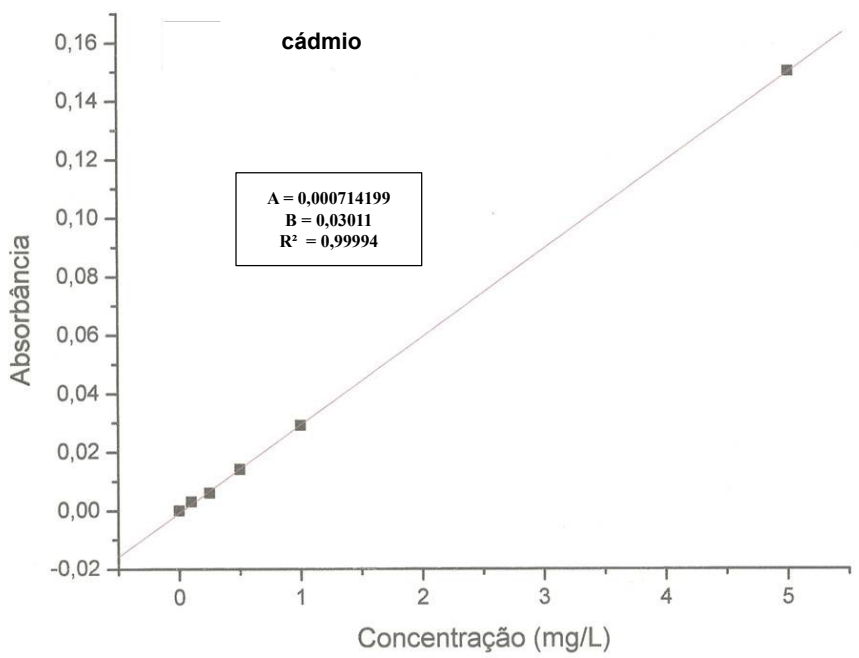

Figura 3. Curva-padrão utilizada para se estabelecer as concentrações de $\mathrm{Ni}^{2+}$ disponível das amostras de folhas, segundo a média dos valores das amostras em triplicatas, em $\lambda=232,0 \mathrm{~nm}$.

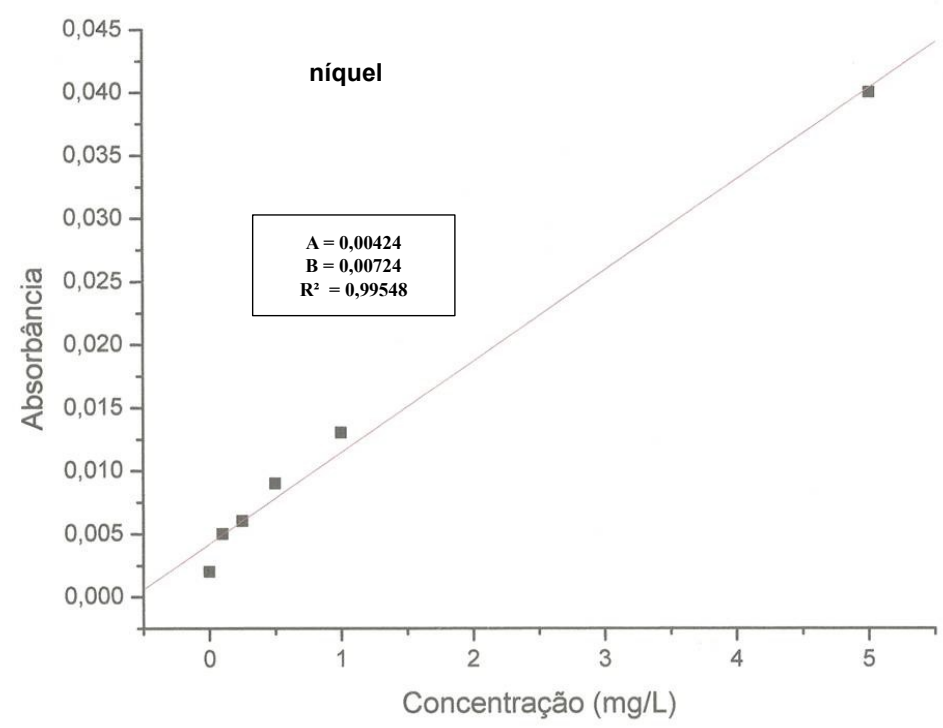

Quadro 6. Resultados obtidos para a concentração dos metais $\mathrm{Mn}^{2+}, \mathrm{Cd}^{2+} \mathrm{e} \mathrm{Ni}^{2+}$ nos extratos das plantas analisados, segundo a média de suas triplicatas.

\begin{tabular}{|c|c|c|c|}
\hline Planta & {$\left[\mathbf{M n}^{2+}\right] \mathbf{~} \mathbf{g ~ k g}^{-1}$} & {$\left[\mathbf{C d}^{2+}\right] \mathbf{~ m g ~ k g}$} & {$\left[\mathbf{N i}^{\mathbf{2}}\right] \mathbf{~ m g ~ k g}^{-1}$} \\
\hline pinheiro & 5,0 & $<0,5$ & 32,5 \\
\hline bananeira & 156,5 & $<0,5$ & 20,5 \\
\hline mangueira & 2590,0 & $<0,5$ & 26,5 \\
\hline goiabeira & 5,0 & $<0,5$ & 21,0 \\
\hline abacateiro & 109,0 & $<0,5$ & 50,5 \\
\hline
\end{tabular}

A partir da análise desses quadros se nota o seguinte comportamento para as folhas processadas com relação à concentração de manganês: pinheiro e goiabeira, teor muito baixo; 
bananeira, teor baixo; mangueira, teor extremamente elevado e abacateiro com teor no intervalo ideal.

Quanto às concentrações do metal cádmio, apesar dos teores determinados se encontrarem no limite de detecção do EAA, expressos em $\mathrm{mg} \mathrm{L}^{-1}$, quando se processa a transformação dessa unidade para a unidade padrão desse tipo de ensaio $\left(\mathrm{mg} \mathrm{kg}^{-1}\right)$, nota-se que todos os valores obtidos são mais elevados do que o máximo permitido (o fator de conversão $\mathrm{mg} \mathrm{kg}^{-1}=\mathrm{mg} \mathrm{L}^{-1} \times 2$, como se encontra em SILVA, 2009, p.159).

Para o metal níquel, os ensaios revelaram que todas as amostras possuem concentrações elevadas do mesmo sendo que, no caso das folhas de abacateiro, essa concentração é dez vezes maior do que o máximo permitido.

Destacam-se os elevados teores dos três metais obtidos da análise das folhas de mangueira. Essa árvore se encontra posicionada por detrás de uma série de exaustores sem filtros adequados de diversos laboratórios de análises químicas (Figura 4), cujos experimentos liberam vapores, inclusive, de metais potencialmente tóxicos.

Figura 4. Série de exaustores pelos quais emanam, dentre outros, metais potencialmente tóxicos.

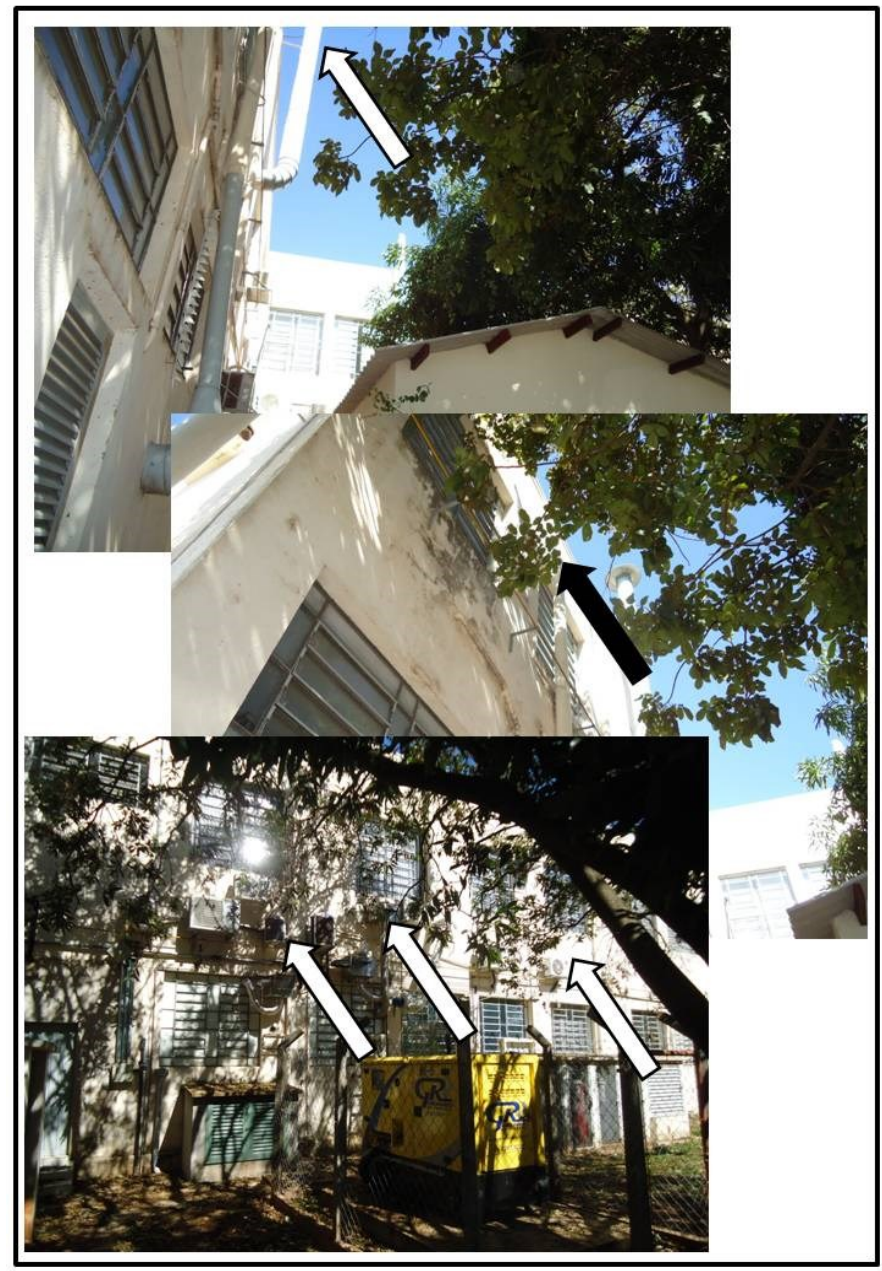

FONTE: IMAGEM DOS AUTORES 


\section{CONCLUSÕES}

Da análise realizada para se determinar os teores de metais nas folhas de árvores do Instituto de Biociências, Letras e Ciências Exatas, do campus da UNESP, de São José do Rio Preto constatou-se que todos os extratos apresentaram teores elevados dos metais cádmio e níquel. As folhas dessas árvores, com certeza estão absorvendo os metais do ar. Constatou-se, também, deficiência do metal manganês nas folhas de pinheiro, goiabeira e bananeira e se recomenda, para as duas últimas árvores, o uso de insumos agrícolas para a correção desse déficit.

Cabe destacar que as folhas de mangueira apresentaram elevadas concentrações de todos os metais sendo que a árvore se encontra posicionada de tal forma a receber a ação direta e contaminante de compostos gerados por laboratórios de análise química. Nesse caso, ou se providenciam filtros adequados para se conter as emanações dos mesmos, ou se aconselha a não se consumir os frutos. A primeira solução seria, com certeza, a mais correta, uma vez que esses compostos são dispersos no ar e podem, inclusive, estar sendo inalados pela comunidade universitária não existindo, nesse caso em particular, nenhum controle ou estudo sobre prováveis prejuízos gerados. Cabe lembrar que tanto o cádmio, quanto o níquel são considerados carcinogênicos.

Conclui-se que o método empregado se mostrou satisfatório ao objetivo do projeto sendo que os resultados revelaram uma situação que pode ser bem comum, ou seja, a contaminação de plantas por resíduos químicos em qualquer centro universitário ou de pesquisa e não somente próximas a polos industriais.

\section{REFERÊNCIAS BIBLIOGRÁFICAS}

ALVES, L. Manganês. Brasil Escola. 2014. Disponível em:

http://www.brasilescola.com/quimica/manganes.htm. Acesso: 14/07/2015.

BelLUTA, I., TOFOLI, L. A., CORRÊA, L. C., CARVALHO, L. R., SILVA, A. M. M. Impactos provocados por metais potencialmente tóxicos dissolvidos em água e em sedimentos no Córrego do Cintra - Botucatu-SP. Salusvita, Bauru, v. 27, n. 2, p. 239-258, 2008. Disponível em: http://www.usc.br/biblioteca/salusvita/salusvita_v27_n2_2008_art_07.pdf. Acesso em: 15/10/2015.

BERNARDI, Alberto Carlos de Campos et al. Comparação de técnicas analíticas para a extração de potássio de amostras de tecido vegetal com água e soluções ácidas concentradas e diluídas. Eclet. Quím. vol.35 n.2 São Paulo 2010.

BRAGA, Gastão Ney Monte. Toxidez de Manganês nas Plantas. NA SALA COM GISMONTI. Assuntos sobre Agronomia. 2011. Disponível em:

http://agronomiacomgismonti.blogspot.com.br/2011/06/toxidez-de-manganes-nasplantas.html. Acesso: 14/10/2015. 
CARNIERI, Iolanda Marina Ramos Soares de Almeida et al. Projeto de Ext. Univer. Solo Planta (1999-2007). Disponível em: http://www.soloplan.agrarias.ufpr.br/tiposdeanalise. Acesso em: $16 / 11 / 2015$.

Companhia de Tecnologia de Saneamento Ambiental - CETESB. Cádmio e seus componentes. Ficha de informação toxicológica, 2012. Disponível em: http://www.cetesb.sp.gov.br/userfiles/file/laboratorios/fit/cadmio.pdf..Acesso em: 25/01/2016.

Companhia de Tecnologia de Saneamento Ambiental - CETESB. Manganês. Ficha de informação toxicológica, 2012. Disponível em:

http://www.cetesb.sp.gov.br/userfiles/file/laboratorios/fit/manganes.pdf.

Acesso: 14/01/2016.

Companhia de Tecnologia de Saneamento Ambiental - CETESB. Níquel e seus compostos.

Ficha de informação toxicológica, 2012. Disponível em:

http://www.cetesb.sp.gov.br/userfiles/file/laboratorios/fit/niquel.pdf. Acesso em:

23/01/2016.

DIÁRIO OFICIAL DA UNIÃO. 2013. Resolução ANVISA no 42. Disponível em: http://www.agricultura.gov.br/arq_editor/file/CRC/Resolu\%C3\%A7\%C3\%A30\%2042\%20\%20ANVISA.pdf . Acesso: 15/01/2016.

E-CENTRO. CENTRO DE ARTIGOS. Fontes de níquel na sua dieta. 2012. Disponível em: http://centrodeartigos.com/dieta/artigo-10795.html. Acesso: 23/01/2016.

FAQUIN, Valdemar. Diagnose do estado nutricional das plantas. Curso de Pós-Graduação "Lato Sensu" (Especialização) a Distância: Fertilidade do Solo e Nutrição de Plantas no Agronegócio. Lavras: UFLA/FAEPE, 2002. Disponível em:

http://www.dcs.ufla.br/site/_adm/upload/file/pdf/Prof_Faquin/Diagnose\%20do\%20Estado\%2 ONutricional\%20das\%20Plantas.pdf. Acesso: 05/02/2016.

GOVERNO DO BRASIL/CONAMA. Metais pesados no ambiente decorrente da aplicação de lodo de esgoto em solo agrícola. Disponível em:

http://www.mma.gov.br/port/conama/processos/CB5F6214/LODOMETAL.pdf.

Acesso em: 15/08/2015.

GUIMARÃES, Marcelo et al. Toxicidade e tolerância ao cádmio em plantas. Revista Trópica Ciências Agrárias e Biológicas. o․ 3, V. 1, pg. 58, 2008. Disponível em:

http://www.ccaa.ufma.br/revistatropica/artigos\%20_vol\%202_\%20nr\%202/agronomia/toxida de_e_toler_agro_re.pdf._Acesso em: 16/07/2015.

LABORSOLO. Micronutrientes: conhecendo o níquel. 2013. Disponível em:

http://www.laborsolo.com.br/site/dris/micronutrientes-conhecendo-o-niquel/.

Acesso: 23/01/2016.

MALLAGOLI, Ellen Del Maschio et al. Teores elevados de metais potencialmente tóxicos em amostras de fertilizantes, 2013. 
MARTINS, Letícia Manolio de Paula. Valores de referência para metais potencialmente tóxicos em sedimentos e moluscos filtradores no Rio Ribeira de Iguape. Dissertação de Mestrado USP - Programa de Pós Graduação em Ciência Ambiental. 103f. Il. 2012. Disponível em: file:///C:/Users/Samara/Downloads/LeticiaManolioversaocorrigida.pdf. Acesso em: 25/01/2016.

MIGUEL JUNIOR, Armando. Cádmio - Intoxicação. Medicina Geriátrica, 2008. Disponível em:http://www.medicinageriatrica.com.br/2008/01/14/camdio-intoxicacao/

Acesso: 25/01/2016.

MOURA, Tiago Augusto. Relatório Parcial, 2009. Disponível em:

http://www.mma.gov.br/port/conama/processos/10F798CF/RelatorioParcial_Mapa_CNPq_Th iagoAugustoMouraEsalq_Usp.pdf._Acesso em: 10/02/2016.

PCEX. Perigos do níquel, 2010. Disponível em:http://www.pcex.com.br/niquel.html. Acesso: 23/01/2016.

PRATES, Helena Magalhães. Avaliação do teor de manganês solúvel e disponível em amostras de solos do Estado de São Paulo. Trabalho de Conclusão de Curso (Universidade Estadual Paulista, Instituto de Biociências, Letras e Ciências Exatas). 47f, anexo. 2011.

ROCHA, Renan Azevedo da, AFONSO, Julio Carlos. Manganês. Química Nova na Escola. Vol. 34, $\mathrm{N}^{\circ} 2$, p. 103-105, 2012. Disponível em: http://qnesc.sbq.org.br/online/qnesc34_2/11-EQ-2311.pdf. Acesso: 14/02/2016.

SANTIAGO, Emerson. Manganês. 2006. Disponível em:

http://www.infoescola.com/elementos-quimicos/manganes/. Acesso: 14/02/2016.

SILVA, Fabio Cesar. Manual de análises químicas de solos, plantas e fertilizantes. Embrapa Solos e Embrapa Informática Agropecuária, 2a edição, 2009. 627p.

VENEZUELA, Tereza Cristina. Determinação de contaminantes metálicos (metal tóxico) num solo adubado com composto de lixo em área olerícola no município de Nova Friburgo, 2001. Disponível em: http://www.arca.fiocruz.br/bitstream/icict/4721/2/575.pdf. Acesso em: 10/01/2016.

VIEIRA, Geraldo Henrique Martins. Nutrição de plantas. Manganês. 2011. Disponível em: http://pt.slideshare.net/GeraldoHMV/apresentao-mangans. Acesso: 14/02/2016. 